\title{
Efeito da Palha de Cana-de-Açúcar e do Tamanho dos TUbÉRCulos NA BIOMASSA DAS EsTruturas SUbTERRÂNEAS DE Cyperus rotundus
}

\author{
Effect of Sugar Cane Straw and Tuber Size on the Subterranean System of \\ Cyperus rotundus
}

NOVO, M.C.S.S. ${ }^{2}$, VICTÓRIA FILHO, R. ${ }^{3}$, LAGO, A.A. ${ }^{4}$ e LANGBECK, F.M. ${ }^{5}$

\begin{abstract}
RESUMO - O experimento foi realizado com o objetivo de avaliar o efeito da adição de palha de cana-de-açúcar RB855156 nas quantidades correspondentes a 0,0, 5,0, 10,0 e 15,0 t ha-1 nas biomassas das estruturas subterrâneas de plantas de tiririca provenientes de tubérculos de tamanho pequeno $(0,22$ a $0,34 \mathrm{~g})$ e grande $(1,01$ a $1,14 \mathrm{~g})$, plantados em maio, julho e setembro. Para cada época de plantio, a cada 28 até 84 dias, as partes subterrâneas da tiririca foram separadas nas diferentes estruturas, sendo determinadas suas biomassas fresca e seca. De modo geral, o tamanho maior dos tubérculos favoreceu o desenvolvimento da parte subterrânea, e plantas originadas de tubérculos de tamanho grande apresentaram maiores biomassas. A adição de palha de cana-de-açúcar causou redução no desenvolvimento das diferentes estruturas subterrâneas, seguindo uma equação de segundo grau. Verificouse que as biomassas foram maiores no plantio de setembro, exceto para biomassa fresca de tubérculos, que foi maior em maio. Com relação ao efeito de época de amostragem, foram observados aumentos lineares em função do tempo para todas as variáveis analisadas.
\end{abstract}

Palavras-chave: tiririca, rizoma, raiz.

\begin{abstract}
The experiment was carried out to evaluate the effect of different amounts of sugar cane straw on the biomass of the subterranean structures of purple nutsedge deriving from small $(0.22$ to $0.34 \mathrm{~g})$ and large $(1.01$ to $1.14 \mathrm{~g})$ sized tubers, planted at different times of the year. Dormant purple nutsedge tubers of small and large sizes were planted in plastic pots with clay soil in May, July and September, and RB855156 sugar cane straw was added in quantities corresponding to 0.0, 5.0, 10.0 and 15.0 t ha $\mathrm{H}^{-1}$. For each planting period, at every 28 day interval up to 84 days, the subterranean parts of the purple nutsedge were separated into their different structures and their fresh and dry biomasses were determined. In general, the larger size of the tubers favored the development of the subterranean parts. It was noted that the plants originated from large sized tubers presented greater fresh and dry biomasses. The addition of increasing quantities of sugar cane straw reduced the growth of the different subterranean structures following a second degree equation. Greater fresh and dry biomasses were observed on the September planting, except for the fresh biomass of the tubers, which was greater in May. Sampling periods caused linear increases in function of time for all the variables studied.
\end{abstract}

Key words: purple nutsedge, rhizome, root.

Recebido para publicação em $1^{\circ} .2 .2005$ e na forma revisada em 5.9.2005.

Pesquisadora Científica do Centro de Ecofisiologia e Biofísica do Instituto Agronômico (IAC), 13001-970 Campinas, SP, $<$ mcdesalvo@hotmail.com>; ${ }^{3}$ Prof. Titular do Departamento de Produção Vegetal, ESALQ-USP, 13418-900 Piracicaba, SP; ${ }^{4}$ Pesquisador Científico, IAC, Campinas, SP; ${ }^{5}$ Graduando em Ciências Biológicas, PUC-Campinas. 


\section{INTRODUÇÃO}

A tiririca é uma das principais infestantes dos canaviais, sendo considerada uma das mais prejudiciais às culturas de todo o mundo (Holm et al., 1977), por sua ampla distribuição, capacidade de competição, agressividade e pela dificuldade em ser controlada ou erradicada (Stoller \& Sweet, 1987). A espécie produz poucas sementes viáveis (Justice \& Whitehead, 1946), sendo seu principal método de propagação o vegetativo, por meio de bulbos basais e tubérculos (Miles et al., 2002).

No Estado de São Paulo, devido principalmente a problemas sanitários e ambientais, foram estabelecidas, por legislação, normas para a colheita da cana-de-açúcar. A queima da palha da cana-de-açúcar deverá ser eliminada gradualmente e substituida por colheita mecanizada, a qual deixa uma camada espessa de palha sobre o solo, afetando as condições químicas, físicas e biológicas do ambiente agrícola. As modificações do ambiente físico e químico afetam a brotação e o crescimento das plantas daninhas e a ação dos herbicidas no controle destas (Azania et al., 2002). No caso da tiririca, há relatos de que, em condições de colheita mecanizada, ocorre redução temporária no número de brotações, porém ela não é acompanhada de diminuição na biomassa subterrânea (Silva et al., 2003).

Na década de 1970, Hammerton (1975 a, b, c) realizou alguns trabalhos sobre o efeito do tamanho de tubérculos de tiririca na sua brotação e desenvolvimento, mas a pesquisa não teve continuidade. Entretanto, para plantas graníferas há diversos trabalhos - como os de Andersen (1970) e Black (1957) - demonstrando que plantas oriundas de sementes de tamanho grande apresentaram maior crescimento e desenvolvimento; em todos eles há restrições à generalização, devido ao efeito do ambiente e das condições de solo (Gelmond, 1978).

O experimento foi realizado com o objetivo de avaliar o efeito de diferentes quantidades de palha de cana-de-açúcar nas biomassas das estruturas subterrâneas de plantas de tiririca provenientes de tubérculos de tamanho pequeno e grande, plantados em diferentes épocas do ano.

\section{MATERIAL E MÉTODOS}

Nos meses de maio, julho e setembro de 2003, no Centro Experimental do Instituto Agronômico de Campinas, SP, foram coletadas plantas de tiririca e selecionados tubérculos dormentes, túrgidos, com aspecto sadio e que não apresentassem danos físicos. Os tubérculos foram separados, quanto ao tamanho, em grande $(1,01$ a $1,14 \mathrm{~g})$ e pequeno $(0,22$ a $0,34 \mathrm{~g})$, acondicionados em latas de alumínio e mantidos sob refrigeração por no máximo três dias até o plantio. Da mesma área de onde foram retiradas as plantas de tiririca foi coletado solo na profundidade de até $0,2 \mathrm{~m}$, que foi peneirado sob crivo fino e colocado em vasos plásticos com capacidade para 6 litros, com furos para percolação da solução do solo. Não foi utilizado corretivo ou fertilizante. As características químicas e físicas do solo das coletas realizadas em maio, julho e setembro são apresentadas na Tabela 1 .

O experimento foi instalado na casa de vegetação do Centro de Ecofisiologia e Biofísica (Campinas-SP) em 27/5, 3/7 e 8/9/2003 e disposto em blocos ao acaso, com quatro repetições. Os tratamentos consistiam na combinação entre o tamanho de tubérculo de tiririca, pequeno e grande, e as quantidades de palha de cana-de-açúcar RB855156, equivalentes a $0,0,5,0,10,0$ e $15,0 \mathrm{tha}^{-1}$, que foram adicionadas à superfície do solo. Para cada tratamento foram plantados, em cada vaso, nas datas descritas, seis tubérculos de tiririca na profundidade de 0,03 m. Após o plantio dos tubérculos e a colocação da palha, todos os vasos foram irrigados até a percolação.

Em intervalos regulares, de 28 até 84 dias, para cada época de plantio, a parte aérea foi cortada e descartada e retirou-se a terra com jato de água, sob pressão, para se obter apenas o sistema subterrâneo. Após a lavagem, este foi seco em papel absorvente, separado nas diferentes estruturas (raiz, rizomas, bulbos basais e tubérculos maduros e imaturos), avaliando-se suas biomassas fresca e seca. Para separar tubérculos quanto à sua maturidade foi usado o conceito de Jordan-Molero \& Stoller (1978), que consideram os tubérculos imaturos quando são de cor branca e maduros quando de cor preta ou marrom-escura. Diariamente, foram monitoradas as temperaturas máximas 
Tabela 1 - Resultados das análises de fertilidade e de granulometria do solo de amostras coletadas na camada entre 0,0 e $0,2 \mathrm{~m}$ de profundidade, nas diferentes épocas de instalação do experimento. Campinas-SP, 2003

\begin{tabular}{|c|c|c|c|c|c|c|c|c|c|c|}
\hline \multirow{3}{*}{$\begin{array}{l}\text { Data de } \\
\text { plantio }\end{array}$} & \multicolumn{10}{|c|}{ Macronutriente } \\
\hline & \multirow{2}{*}{$\begin{array}{c}\mathrm{P} \\
\left(\mathrm{mg} \mathrm{dm}^{-3}\right)\end{array}$} & \multirow{2}{*}{$\begin{array}{c}\text { M.O. } \\
\left(\mathrm{g} \mathrm{dm}^{-3}\right)\end{array}$} & \multirow{2}{*}{$\begin{array}{c}\mathrm{pH} \\
\left(\mathrm{CaCl}_{2}\right)\end{array}$} & $\mathrm{K}$ & $\mathrm{Ca}$ & $\mathrm{Mg}$ & $\mathrm{H}+\mathrm{Al}$ & SB & CTC & \multirow{2}{*}{$\begin{array}{c}\mathrm{V} \\
(\%)\end{array}$} \\
\hline & & & & \multicolumn{6}{|c|}{$\left(\mathrm{mmol}_{\mathrm{c}} \mathrm{dm}^{-3}\right)$} & \\
\hline $27 / 5$ & 56 & 31 & 5,7 & 4,5 & 35 & 14 & 20 & 53,5 & 73,7 & 73 \\
\hline $3 / 7$ & 50 & 22 & 4,9 & 1,3 & 21 & 7 & 31 & 29,3 & 60,1 & 49 \\
\hline $8 / 9$ & 105 & 26 & 5,7 & 3,3 & 43 & 16 & 28 & 62,3 & 90,1 & 69 \\
\hline \multirow{3}{*}{$\begin{array}{c}\text { Data } \\
\text { de } \\
\text { plantio }\end{array}$} & \multicolumn{6}{|c|}{ Micronutriente } & \multicolumn{4}{|c|}{ Granulometria } \\
\hline & $\mathrm{B}$ & $\mathrm{Cu}$ & $\mathrm{Fe}$ & & $\mathrm{Mn}$ & $\mathrm{Zn}$ & areia tots & & & argila \\
\hline & \multicolumn{6}{|c|}{$\frac{\mathrm{Fe}}{\left(\mathrm{mg} \mathrm{dm}^{-3}\right)}$} & \multicolumn{4}{|c|}{$\left(\mathrm{g} \mathrm{kg}^{-1}\right)$} \\
\hline $27 / 5$ & 0,39 & 5,8 & 8 & & 29,3 & 2,5 & 325 & & 7 & 588 \\
\hline $3 / 7$ & 0,16 & 4,6 & 10 & & 17,3 & 0,9 & 338 & & 9 & 563 \\
\hline $8 / 9$ & 0,51 & 5,6 & 8 & & 28,3 & 2,5 & 245 & & & 525 \\
\hline
\end{tabular}

M.O.= matéria orgânica; $\mathrm{SB}=$ soma de base $\mathrm{CTC}=$ capacidade de troca catiônica; $\mathrm{V}=$ saturação por base.

e mínimas do ar, do solo descoberto e com as diferentes quantidades de palha (dados não apresentados).

Para análise estatística, além das variáveis descritas, foram também avaliadas as biomassas fresca e seca do total de tubérculos (maduros + imaturos) e da parte subterrânea total (raiz + rizomas + bulbos basais + tubérculos maduros + tubérculos imaturos). Os dados foram submetidos à análise de variância, usando o teste $\mathrm{F}$; quando significativos, os efeitos dos tamanhos dos dissemínulos e da época de plantio tiveram suas médias comparadas pelo teste de Tukey. Para o efeito de época de avaliação e de dose de palha, foi empregada a análise de regressão.

\section{RESULTADOS E DISCUSSÃO}

Não foi observada diferença estatística quanto às biomassas fresca e seca de tubérculos maduros e imaturos (dados não apresentados). Todas as estruturas subterrâneas da tiririca, provenientes de tubérculos grandes, apresentaram biomassas fresca e seca maiores que as dos pequenos (Tabelas 2, 3 e 4, médias). Há relatos indicando que o tamanho da semente afeta a emergência das plântulas (Lafond \& Baker, 1986), o desenvolvimento (Evans \& Bhatt, 1977), o tamanho final da planta e a produção (Liu \& Owen, 2003), sendo a maioria em gramineas e leguminosas.
Weis (1982) observou acréscimo na taxa de germinação e na biomassa de Mirabilis hirsuta com o aumento da biomassa da semente. Observou também que havia relação direta entre o tamanho da semente, a taxa de crescimento e a biomassa da planta em função da maior quantidade de reservas existente nos disseminulos. A maior quantidade de reserva nutritiva favorecia a planta no início de seu desenvolvimento, quando ainda seu sistema fotossintético era incipiente. Entretanto, para muitas espécies, a vantagem inicial de possuir maior reserva metabólica é afetada pela época de emergência, pela forma e pela taxa de crescimento da planta, bem como pelo tipo de cobertura do solo (Gross, 1984).

Foi observada interação significativa entre época de plantio e tamanho de disseminulos apenas para biomassa fresca do total de tubérculos e biomassa seca de rizomas (Tabela 2). Em quaisquer das épocas de plantio, as plantas provenientes de tubérculos grandes produziram maiores biomassas. A biomassa fresca do total de tubérculos de plantas provenientes tanto de tubérculos pequenos quanto de grandes foi menor no plantio de julho, não havendo, para tubérculos pequenos, diferença quando o plantio foi feito em maio ou em setembro. No entanto, para tubérculos grandes, a biomassa fresca do total de tubérculos foi maior em maio que em setembro (Tabela 2). Segundo Jordan-Molero \& Stoller (1978), nos

Planta Daninha, Viçosa-MG, v. 23, n. 3, p. 437-448, 2005 
meses mais frios, como observado em julho, ocorre diminuição no desenvolvimento da tiririca devido à redução na intensidade de luz; contudo, deve-se considerar também o efeito térmico, pois a tiririca é bastante sensivel à baixa temperatura (Wills, 1975). Martins et al. (1999) relataram também que em condições onde há maiores oscilações de temperatura, luz e umidade, como observado em maio e setembro, ocorre menor dormência de sementes de plantas daninhas e, portanto, maior brotação e desenvolvimento. Com relação à biomassa seca de rizomas, para qualquer tamanho de tubérculo, maiores valores foram observados no plantio de setembro e menores em julho (Tabela 2).

Hammerton (1975c) verificou que, para as condições da Jamaica, o crescimento dos rizomas iniciava-se e era mais rápido quando o comprimento do dia aumentava, resultando também em aumento no número de tubérculos e de brotação. Em dias curtos, quando o crescimento dos rizomas, a produção de tubérculos e o processo fotossintético eram menores, o florescimento era retardado até que um número mínimo de tubérculos fosse formado. Como o florescimento e a produção de sementes não são meios importantes para a propagação da tiririca, um mecanismo pelo qual a formação de tubérculos tem prioridade sobre a produção de inflorescência, quando as fontes fotossintéticas são relativamente escassas, é uma adaptação valiosa.

Os resultados do efeito da interação entre tamanho de tubérculos e quantidade de palha quanto às biomassas fresca e seca das diferentes estruturas subterrâneas são apresentados, respectivamente, nas Tabelas 3 e 4. Exceto para raiz, as biomassas fresca e seca, com quaisquer das quantidades de palha, foram

Tabela 2 - Efeito do tamanho dos tubérculos de tiririca na biomassa fresca (BF) de rizomas, e da interação entre tamanho dos tubérculos e época de plantio na biomassa fresca de total de tubérculos e seca de rizomas. Campinas-SP, 2003

\begin{tabular}{|c|c|c|c|c|c|c|c|c|c|}
\hline \multirow{2}{*}{$\begin{array}{l}\text { Tamanho } \\
\text { dos } \\
\text { tubérculos }\end{array}$} & \multirow{2}{*}{$\begin{array}{c}\mathrm{BF} \\
\text { rizomas } \\
\text { média }\end{array}$} & \multicolumn{4}{|c|}{$\begin{array}{l}\text { Biomassa fresca do total de tubérculos } \\
\qquad(\mathrm{g})\end{array}$} & \multicolumn{4}{|c|}{$\begin{array}{c}\text { Biomassa seca de rizomas } \\
(\mathrm{g})\end{array}$} \\
\hline & & Maio & Julho & Setembro & Média & Maio & Julho & Setembro & Média \\
\hline Pequeno & $2,27 \mathrm{~b}$ & $15,52 \mathrm{bA}^{1 /}$ & $5,23 \mathrm{bB}$ & $14,67 \mathrm{bA}$ & $11,81 \mathrm{~b}$ & $0,25 \mathrm{bB}$ & $0,12 \mathrm{cB}$ & $0,46 \mathrm{aB}$ & $0,27 \mathrm{~b}$ \\
\hline Grande & $2,58 \mathrm{a}$ & $22,06 \mathrm{aA}$ & $9,75 \mathrm{aC}$ & $20,13 \mathrm{aB}$ & $17,33 \mathrm{a}$ & $0,40 \mathrm{bA}$ & $0,16 \mathrm{cA}$ & $0,49 \mathrm{aA}$ & $0,35 \mathrm{a}$ \\
\hline
\end{tabular}

${ }^{1 /}$ Médias seguidas por letra maiúscula na linha, que comparam o efeito da época de plantio de tubérculo para cada tamanho de tubérculo, e por letra minúscula na coluna, que comparam o efeito do tamanho de tubérculo em cada época de plantio, não diferem entre si pelo teste de Tukey a $5 \%$.

Tabela 3 - Efeito da interação entre quantidade de palha e tamanho de tubérculos de tiririca nas biomassas frescas de raiz, total de tubérculos e parte subterrânea total

\begin{tabular}{|c|c|c|c|c|c|c|}
\hline \multirow{3}{*}{$\begin{array}{l}\text { Tamanho } \\
\text { dos } \\
\text { tubérculos }\end{array}$} & \multicolumn{6}{|c|}{ Biomassa fresca de raiz $(\mathrm{g})$} \\
\hline & \multicolumn{4}{|c|}{ Quantidade de palha } & \multirow{2}{*}{ Média } & \multirow{2}{*}{$\begin{array}{l}\text { Equações de ajuste e coeficiente de } \\
\text { determinaçãa }{ }^{1 /}\end{array}$} \\
\hline & $0,0 \mathrm{t} \mathrm{ha}^{-1}$ & $5,0 \mathrm{tha}^{-1}$ & $10,0 \mathrm{t} \mathrm{ha}^{-1}$ & $15,0 \mathrm{t} \mathrm{ha}^{-1}$ & & \\
\hline Pequeno & $14,49 \mathrm{~b}^{2 /}$ & $12,38 \mathrm{a}$ & $10,86 \mathrm{~b}$ & $11,75 \mathrm{~b}$ & $12,37 \mathrm{~b}$ & $Y=14,58-0,644 x+0,030 x^{2} \quad R^{2}=97,66 \%$ \\
\hline \multirow[t]{2}{*}{ Grande } & $19,24 \mathrm{a}$ & $12,95 \mathrm{a}$ & $12,69 \mathrm{a}$ & $15,08 \mathrm{a}$ & $14,99 \mathrm{a}$ & $Y=19,07-1,56 x+0,087 x^{2} \quad R^{2}=97,94 \%$ \\
\hline & \multicolumn{6}{|c|}{ Biomassa fresca de total de tubérculos $(\mathrm{g})$} \\
\hline Pequeno & $12,82 \mathrm{~b}^{2 /}$ & $11,34 \mathrm{~b}$ & $11,30 \mathrm{~b}$ & $11,78 \mathrm{~b}$ & $11,81 \mathrm{~b}$ & $Y=12,77-0,36 x+0,020 x^{2} R^{2}=97,15 \%$ \\
\hline \multirow[t]{2}{*}{ Grande } & $20,19 \mathrm{a}$ & $15,67 \mathrm{a}$ & $16,43 \mathrm{a}$ & $17,05 \mathrm{a}$ & $17,33 \mathrm{a}$ & $Y=19,92-0,94 x+0,052 x^{2} \quad R^{2}=87,59 \%$ \\
\hline & \multicolumn{6}{|c|}{ Biomassa fresca de parte subterrânea total (g) } \\
\hline Pequeno & $34,67 \mathrm{~b}^{2 /}$ & $27,40 \mathrm{~b}$ & $25,61 \mathrm{~b}$ & $27,06 \mathrm{~b}$ & $28,69 \mathrm{~b}$ & $\mathrm{Y}=34,56-1,80 \mathrm{x}+0,087 \mathrm{x}^{2} \quad \mathrm{R}^{2}=99,49 \%$ \\
\hline Grande & $45,72 \mathrm{a}$ & $32,77 \mathrm{a}$ & $32,53 \mathrm{a}$ & $35,43 \mathrm{a}$ & $36,61 \mathrm{a}$ & $Y=45,24-2,996 x+0,16 x^{2} \quad R^{2}=96,05 \%$ \\
\hline
\end{tabular}

${ }^{1 /}$ Equações de regressão e coeficientes de determinação para o efeito da quantidade de palha adicionada dentro de cada tamanho de tubérculo. ${ }^{2 /}$ Médias seguidas por letras iguais na coluna, que comparam o efeito do tamanho de tubérculo para cada quantidade de palha adicionada, não diferem entre si pelo teste de Tukey a $5 \%$. 
Tabela 4 - Efeito da interação entre quantidade de palha ao solo e tamanho de tubérculos da tiririca nas biomassas secas de raiz, total de tubérculos e parte subterrânea total

\begin{tabular}{|c|c|c|c|c|c|c|c|}
\hline \multirow{3}{*}{$\begin{array}{l}\text { Tamanho } \\
\text { dos } \\
\text { tubérculos }\end{array}$} & \multicolumn{7}{|c|}{ Biomassa seca de raiz $(\mathrm{g})$} \\
\hline & \multicolumn{4}{|c|}{ Quantidade de palha } & \multirow{2}{*}{ Média } & \multirow{2}{*}{\multicolumn{2}{|c|}{$\begin{array}{c}\text { Equação de ajuste e coeficiente de } \\
\text { determinação } o^{1 /}\end{array}$}} \\
\hline & $0,0 \mathrm{tha}^{-1}$ & $5,0 \mathrm{tha}^{-1}$ & $10,0 \mathrm{t} \mathrm{ha}^{-1}$ & $15,0 \mathrm{t} \mathrm{ha}^{-1}$ & & & \\
\hline Pequeno & $1,51 \mathrm{~b}^{2 /}$ & $1,19 \mathrm{a}$ & $1,16 \mathrm{~b}$ & $1,20 \mathrm{~b}$ & $1,27 \mathrm{~b}$ & $Y=1,50-0,075 x+0,004 x^{2}$ & $\mathrm{R}^{2}=96,95 \%$ \\
\hline \multirow[t]{2}{*}{ Grande } & $2,12 \mathrm{a}$ & $1,37 \mathrm{a}$ & $1,48 \mathrm{a}$ & $1,51 \mathrm{a}$ & $1,62 \mathrm{a}$ & $Y=2,08-0,15 x+0,0078 x^{2}$ & $\mathrm{R}^{2}=87,45 \%$ \\
\hline & \multicolumn{7}{|c|}{ Biomassa seca de total de tubérculos $(\mathrm{g})$} \\
\hline Pequeno & $3,76 \mathrm{~b}^{2 /}$ & $3,62 \mathrm{~b}$ & $3,63 \mathrm{~b}$ & $3,88 \mathrm{~b}$ & $3,72 b$ & Não-significativo & \\
\hline \multirow[t]{2}{*}{ Grande } & $6,31 \mathrm{a}$ & $5,20 \mathrm{a}$ & "5,56 a & $5,82 \mathrm{a}$ & $5,72 \mathrm{a}$ & $Y=6,23-0,23 x+, 014 x^{2}$ & $\mathrm{R}^{2}=81,05 \%$ \\
\hline & \multicolumn{7}{|c|}{ Biomassa seca de parte subterrânea total (g) } \\
\hline Pequeno & $6,87 \mathrm{~b}^{2} /$ & $5,72 \mathrm{~b}$ & $5,75 \mathrm{~b}$ & $6,00 \mathrm{~b}$ & $6,09 \mathrm{~b}$ & $Y=6,87-0,26 x+0,014 x^{2}$ & $\mathrm{R}^{2}=94,53 \%$ \\
\hline Grande & $10,18 \mathrm{a}$ & $7,74 \mathrm{a}$ & $8,08 \mathrm{a}$ & $8,53 \mathrm{a}$ & $8,64 \mathrm{a}$ & $Y=10,05-0,053 x+0,029 x^{2}$ & $\mathrm{R}^{2}=89,87 \%$ \\
\hline
\end{tabular}

1/ Equações de regressão e coeficientes de determinação para o efeito da quantidade de palha adicionada dentro de cada tamanho de tubérculo. ${ }^{2 /}$ Médias seguidas por letras iguais na coluna, que comparam o efeito do tamanho de tubérculo para cada quantidade de palha adicionada, não diferem entre si pelo teste de Tukey a 5\%.

maiores quando as plantas eram provenientes de dissemínulos grandes. O mesmo foi observado para as biomassas fresca e seca de raiz com 0,0 e com a adição de 10,0 e 15,0 t ha-1 de palha à superfície do solo (Tabelas 3 e 4); entretanto, com 5,0 t ha ${ }^{-1}$, não houve efeito de tamanho de tubérculos na biomassa fresca ou seca de raiz. Dados obtidos por Lafond \& Baker (1986) com nove cultivares de trigo também comprovaram que a produção de matéria seca é maior quando as plantas são originadas de semente de tamanho grande. Para as condições do Brasil, Procópio et al. (2001) observaram que o acúmulo de biomassa seca de raízes de feijão aumentou com o uso de sementes maiores. Edwards Junior \& Hartwig (1971) observaram que plantas de soja oriundas de sementes de tamanho pequeno $(9,5 \mathrm{~g} /$ 100 sementes) e médio (13,6 g/ 100 sementes) emergem mais rapidamente e apresentam maior desenvolvimento radicular que as de tamanho grande. Todavia, deve-se considerar que a habilidade da planta em translocar e utilizar as reservas pode exercer influência no tamanho e na biomassa das plântulas. Não foi observada interação entre esses dois fatores para as biomassas fresca e seca de rizomas (dados não apresentados).

Houve efeito depressivo para as biomassas fresca e seca de raiz, total de tubérculos e parte subterrânea total com a adição de palha. Observou-se que as equações que melhor se ajustaram às quantidades de palha adicionadas foram as de segundo grau. De modo geral, o efeito foi mais pronunciado em plantas provenientes de tubérculos grandes, para os quais, com quantidades menores de palha, a redução foi maior (Tabelas 3 e 4).

Os resultados da interação entre tamanho de tubérculos e época de amostragem são apresentados na Figura 1. As biomassas fresca e seca de total de tubérculos, as secas de rizomas e da parte subterrânea total, nas diferentes épocas de avaliação, para ambos os tamanhos de tubérculos, aumentaram linearmente em função do tempo. JordanMolero \& Stoller (1978) também observaram aumento linear no acúmulo de matéria seca da tiririca em função do tempo. Entretanto, essas mesmas biomassas, em todas as épocas analisadas, foram maiores em plantas oriundas de tubérculos grandes.

As interações entre quantidade de palha e época de plantio de tubérculos - nas biomassas fresca e seca das estruturas subterrâneas - são apresentadas, respectivamente, nas Tabelas 5 e 6 . As biomassas frescas de raiz, rizomas e parte subterrânea total, para quaisquer das quantidades de palha, foram maiores no plantio de setembro e menores em julho (Tabela 5). Foi observada maior biomassa fresca de total de tubérculo no plantio de setembro apenas no tratamento sem palha. Com a adição de 10,0 e 15,0 t ha-1 de palha, observou-se maior biomassa fresca de total de tubérculo no plantio de maio.

Planta Daninha, Viçosa-MG, v. 23, n. 3, p. 437-448, 2005 
Tabela 5 - Efeito da interação entre quantidade de palha e épocas de plantio dos tubérculos de tiririca nas biomassas frescas de raiz, rizomas, total de tubérculos e parte subterrânea total

\begin{tabular}{|c|c|c|c|c|c|c|}
\hline \multirow{3}{*}{$\begin{array}{l}\text { Época de } \\
\text { plantio dos } \\
\text { tubérculos }\end{array}$} & \multicolumn{6}{|c|}{ Biomassa fresca de raiz $(\mathrm{g})$} \\
\hline & \multicolumn{4}{|c|}{ Quantidade de palha } & \multirow{2}{*}{\multicolumn{2}{|c|}{$\begin{array}{l}\text { Equação de ajuste e coeficiente de } \\
\text { determinação }^{1 /}\end{array}$}} \\
\hline & $0,0 \mathrm{t} \mathrm{ha}^{-1}$ & $5,0 \mathrm{t} \mathrm{ha}^{-1}$ & $10,0 \mathrm{t} \mathrm{ha}^{-1}$ & $15,0 \mathrm{t} \mathrm{ha}^{-1}$ & & \\
\hline Maio & $14,94 \mathrm{~b}^{2 /}$ & $12,05 \mathrm{~b}$ & $12,32 \mathrm{~b}$ & $14,39 \mathrm{~b}$ & $Y=14,86-0,77 x+0,045 x^{2}$ & $\mathrm{R}^{2}=98,53 \%$ \\
\hline Julho & $6,12 \mathrm{c}$ & $7,30 \mathrm{c}$ & $7,54 \mathrm{c}$ & $9,04 \mathrm{c}$ & $Y=6,15-0,18 x$ & $\mathrm{R}^{2}=93,88 \%$ \\
\hline \multirow[t]{2}{*}{ Setembro } & $29,54 \mathrm{a}$ & $18,65 \mathrm{a}$ & $15,45 \mathrm{a}$ & $16,81 \mathrm{a}$ & $Y=29,39-0,67 x+0,123 x^{2}$ & $\mathrm{R}^{2}=99,60 \%$ \\
\hline & \multicolumn{6}{|c|}{ Biomassa fresca de rizomas (g) } \\
\hline Maio & $3,18 \mathrm{~b}^{2 /}$ & $2,42 \mathrm{~b}$ & $2,23 \mathrm{~b}$ & $2,77 \mathrm{a}$ & $Y=3,19-0,22 x+0,013 x^{2}$ & $\mathrm{R}^{2}=99,76 \%$ \\
\hline Julho & $0,82 \mathrm{c}$ & $0,85 \mathrm{c}$ & $1,08 \mathrm{c}$ & $1,27 \mathrm{~b}$ & $Y=0,76+0,032 x$ & $\mathrm{R}^{2}=93,61 \%$ \\
\hline \multirow[t]{2}{*}{ Setembro } & $5,73 \mathrm{a}$ & $3,40 \mathrm{a}$ & $2,79 \mathrm{a}$ & $2,51 \mathrm{a}$ & $Y=5,66-0,52 x+0,021 x^{2}$ & $\mathrm{R}^{2}=98,48 \%$ \\
\hline & \multicolumn{6}{|c|}{ Biomassa fresca de total de tubérculos (g) } \\
\hline Maio & $19,70 \mathrm{~b}^{2 /}$ & $16,64 \mathrm{a}$ & 18,63 a & $20,18 \mathrm{a}$ & $Y=19,43-0,62 x+0,046 x^{2}$ & $\mathrm{R}^{2}=96,06 \%$ \\
\hline Julho & $7,21 \mathrm{c}$ & $6,51 \mathrm{~b}$ & $7,73 \mathrm{c}$ & $8,52 \mathrm{~b}$ & $Y=6,71+0,10 x$ & $\mathrm{R}^{2}=61,62 \%$ \\
\hline \multirow[t]{2}{*}{ Setembro } & $22,62 \mathrm{a}$ & $17,36 \mathrm{a}$ & $15,22 \mathrm{~b}$ & $14,54 \mathrm{~b}$ & $Y=21,39-0,53 x$ & $\mathrm{R}^{2}=86,65 \%$ \\
\hline & \multicolumn{6}{|c|}{ Biomassa fresca de parte subterrânea total $(\mathrm{g})$} \\
\hline Maio & $34,52 \mathrm{~b}^{2 /}$ & $28,44 \mathrm{~b}$ & $29,65 \mathrm{~b}$ & $32,80 \mathrm{~b}$ & $Y=34,25-1,463 x+0,092 x^{2}$ & $\mathrm{R}^{2}=93,92 \%$ \\
\hline Julho & $14,40 \mathrm{c}$ & $14,49 \mathrm{c}$ & $16,74 \mathrm{c}$ & $19,16 \mathrm{c}$ & $Y=13,72+0,33 x$ & $\mathrm{R}^{2}=89,73 \%$ \\
\hline Setembro & $71,67 \mathrm{a}$ & $47,33 \mathrm{a}$ & $40,82 \mathrm{a}$ & $41,77 \mathrm{a}$ & $Y=71,15-5,72 x+0,23 x^{2}$ & $\mathrm{R}^{2}=99,14 \%$ \\
\hline
\end{tabular}

${ }^{1 /}$ Equações de regressão e coeficientes de determinação para o efeito da quantidade de palha adicionada dentro de cada época de plantio dos tubérculos de tiririca. ${ }^{2 /}$ Médias seguidas por letras iguais na coluna, que comparam o efeito da época de plantio dos tubérculos de tiririca para cada quantidade de palha adicionada, não diferem entre si pelo teste de Tukey a $5 \%$.

Tabela 6 - Efeito da interação entre quantidade de palha e épocas de plantio dos tubérculos de tiririca nas biomassas secas de raiz, rizomas, total de tubérculos e parte subterrânea total

\begin{tabular}{|c|c|c|c|c|c|c|}
\hline \multirow{3}{*}{$\begin{array}{l}\text { Época de } \\
\text { plantio dos } \\
\text { tubérculos }\end{array}$} & \multicolumn{6}{|c|}{ Biomassa seca de raiz $(\mathrm{g})$} \\
\hline & \multicolumn{4}{|c|}{ Quantidade de palha } & \multirow{2}{*}{\multicolumn{2}{|c|}{$\begin{array}{l}\text { Equação de ajuste e coeficiente de } \\
\text { determinação }^{\underline{1}}\end{array}$}} \\
\hline & $0,0 \mathrm{t} \mathrm{ha}^{-1}$ & $5,0 \mathrm{t} \mathrm{ha}^{-1}$ & $10,0 \mathrm{t} \mathrm{ha}^{-1}$ & $15,0 \mathrm{t} \mathrm{ha}^{-1}$ & & \\
\hline Maio & $1,81 \mathrm{~b}^{2 /}$ & $1,16 \mathrm{~b}$ & $1,52 \mathrm{a}$ & $1,58 \mathrm{a}$ & $Y=1,74-0,11 x+0,0071 x$ & $\mathrm{R}^{2}=60,29 \%$ \\
\hline Julho & $0,63 \mathrm{c}$ & $0,69 \mathrm{c}$ & $0,87 \mathrm{~b}$ & $0,89 \mathrm{~b}$ & $\mathrm{Y}=0,63+0,019 \mathrm{x}$ & $\mathrm{R}^{2}=90,46 \%$ \\
\hline \multirow[t]{2}{*}{ Setembro } & $3,02 \mathrm{a}$ & $2,00 \mathrm{a}$ & $1,57 \mathrm{a}$ & $1,61 \mathrm{a}$ & $Y=3,01-0,25 x+0,011 x^{2}$ & $\mathrm{R}^{2}=99,95 \%$ \\
\hline & \multicolumn{6}{|c|}{ Biomassa seca de rizomas $(\mathrm{g})$} \\
\hline Maio & $0,40 \mathrm{~b}^{-2}$ & $0,26 \mathrm{~b}$ & $0,28 \mathrm{~b}$ & $0,36 \mathrm{a}$ & $Y=0,39-0,036 x+0,0023 x^{2}$ & $\mathrm{R}^{2}=96,45 \%$ \\
\hline Julho & $0,11 \mathrm{c}$ & $0,11 \mathrm{c}$ & $0,15 \mathrm{c}$ & $0,17 \mathrm{~b}$ & $Y=0,11+0,0044 x$ & $\mathrm{R}^{2}=92,09 \%$ \\
\hline \multirow[t]{2}{*}{ Setembro } & $0,78 \mathrm{a}$ & $0,44 \mathrm{a}$ & $0,36 \mathrm{a}$ & $0,32 \mathrm{a}$ & $Y=0,71-0,076 x+0,0031 x^{2}$ & $\mathrm{R}^{2}=98,04 \%$ \\
\hline & \multicolumn{6}{|c|}{ Biomassa seca de total de tubérculos (g) } \\
\hline Maio & $5,54 \mathrm{~b}^{-2}$ & $5,07 \mathrm{~b}$ & $5,81 \mathrm{a}$ & $6,43 \mathrm{a}$ & $Y=5,48-0,095 x+0,011 x^{2}$ & $\mathrm{R}^{2}=90,74 \%$ \\
\hline Julho & $2,15 \mathrm{c}$ & $2,27 \mathrm{c}$ & $2,59 \mathrm{~b}$ & $2,84 \mathrm{c}$ & $Y=2,11+0,047 x$ & $\mathrm{R}^{2}=97,23 \%$ \\
\hline \multirow[t]{2}{*}{ Setembro } & $7,40 \mathrm{a}$ & $5,88 \mathrm{a}$ & $5,39 \mathrm{a}$ & $5,28 \mathrm{~b}$ & $Y=7,02-0,14 x$ & $\mathrm{R}^{2}=82,15 \%$ \\
\hline & \multicolumn{6}{|c|}{ Biomassa seca de parte subterrânea total $(\mathrm{g})$} \\
\hline Maio & $8,09 \mathrm{~b}^{2 /}$ & $6,81 \mathrm{~b}$ & $7,87 \mathrm{~b}$ & $8,78 \mathrm{ab}$ & $Y=7,96-0,27 x+0,022 x^{2}$ & $\mathrm{R}^{2}=84,50 \%$ \\
\hline Julho & $3,23 \mathrm{c}$ & $3,53 \mathrm{c}$ & $4,02 \mathrm{c}$ & $4,38 \mathrm{~b}$ & $Y=3,20+0,079 x$ & $\mathrm{R}^{2}=99,21 \%$ \\
\hline Setembro & $14,26 \mathrm{a}$ & $9,86 \mathrm{a}$ & $8,87 \mathrm{a}$ & $8,64 \mathrm{a}$ & $Y=13,08-0,37 x$ & $\mathrm{R}^{2}=77,13 \%$ \\
\hline
\end{tabular}

${ }^{1 /}$ Equações de regressão e coeficientes de determinação para o efeito da quantidade de palha adicionada dentro de cada época de plantio dos tubérculos de tiririca. ${ }^{2 /}$ Médias seguidas por letras iguais na coluna, que comparam o efeito da época de plantio dos tubérculos de tiririca para cada quantidade de palha adicionada, não diferem entre si pelo teste de Tukey a $5 \%$. 

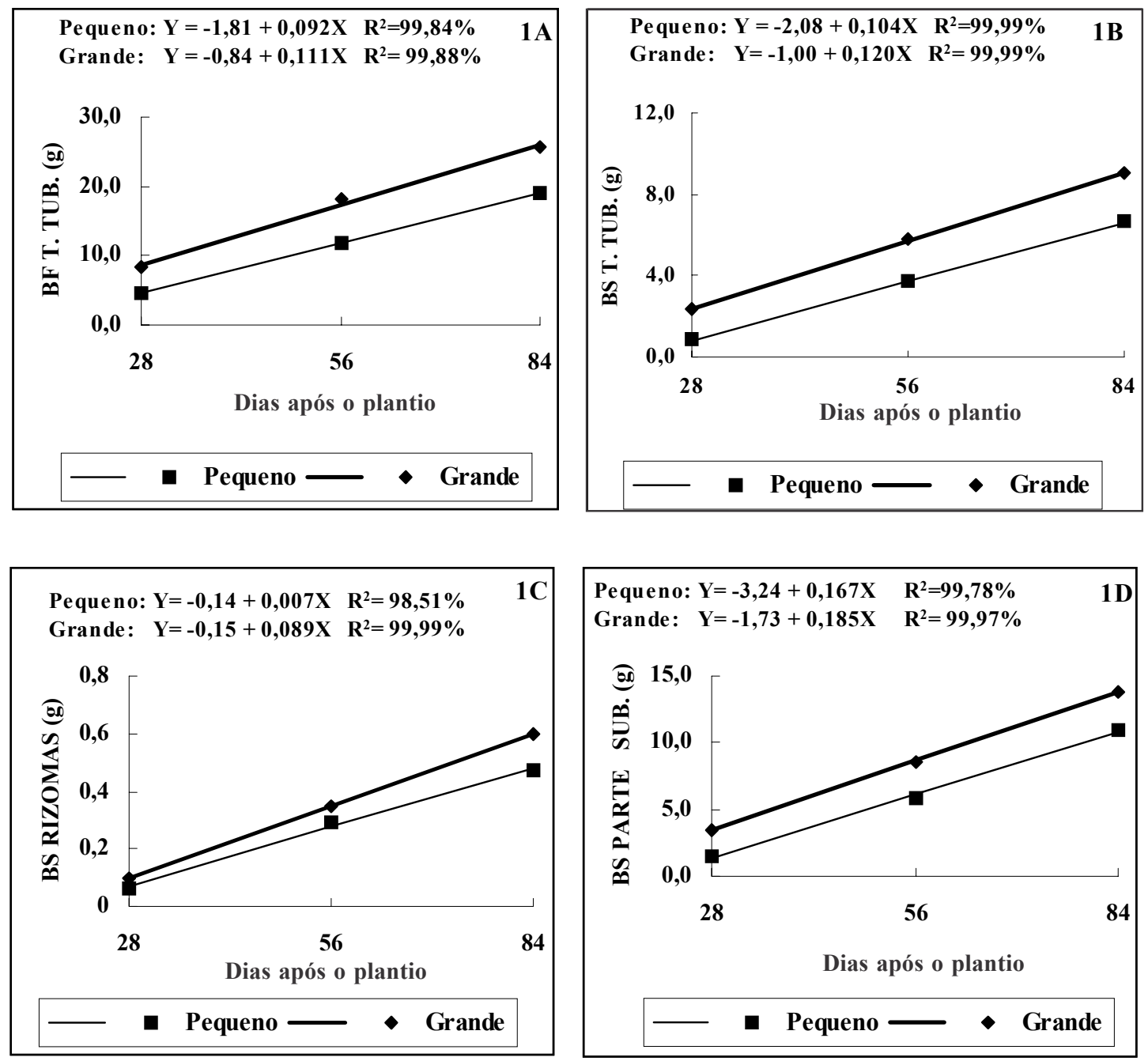

Figura 1 - Efeito da interação entre tamanho de tubérculo e épocas de avaliação para biomassas fresca (BF) e seca (BS) do total de tubérculos (T.TUB.) e biomassas secas de rizomas e parte subterrânea total (PARTE SUB.). Campinas, 2003.

Nos plantios de maio e setembro, observou-se que, com a adição de palha, houve redução nas biomassas frescas de raiz, rizomas e parte subterrânea total de acordo com uma equação do segundo grau. Azania et al. (2002) verificaram que há redução no número de plantas daninhas em áreas cobertas com quantidades de palha superiores a 3,0 t ha ${ }^{-1}$, o que também foi observado por Martins et al. (1999). As biomassas frescas de raiz, rizoma, total de tubérculos e parte subterrânea total aumentaram linearmente com a adição de palha quando plantados em julho. Vidal \& Theisen (1999) observaram que, em áreas cobertas com resíduos vegetais, há menor incidência de luz e menor aquecimento do solo, o que pode interferir no desenvolvimento da planta, exercendo influência nas diferentes etapas do ciclo de vida, como na germinação, no estabelecimento e na reprodução da espécie. No entanto, em solo coberto também é observada menor perda de calor e redução de oscilação térmica. Miles et al. (1996) constataram estímulo na brotação da tiririca quando houve oscilação térmica de 2 a $6{ }^{\circ} \mathrm{C}$. Com menor oscilação térmica, como a do plantio de julho nos vasos com palha, houve menores brotação e biomassa nas outras épocas, porém as plantas que brotaram em função da maior temperatura observada no solo coberto que no 
sem palha tiveram suas biomassas linearmente aumentadas. A biomassa fresca de tubérculos foi linearmente reduzida com a adição de palha no plantio de setembro.

A biomassa seca de raiz foi maior no plantio de setembro e menor no de julho, com qualquer quantidade de palha adicionada (Tabela 6). O mesmo ocorreu com a biomassa seca de rizoma e de parte subterrânea total até a adição de $10,0 \mathrm{t} \mathrm{ha}^{-1}$ de palha. Com $15,0 \mathrm{t} \mathrm{ha}^{-1}$ de palha, não houve diferença para biomassa seca de rizomas entre o plantio de setembro e o de maio, mas o de julho produziu biomassa menor. Para biomassa seca de total de tubérculos, verificou-se que, no tratamento sem palha, o plantio de setembro propiciou biomassas superiores às de maio (Tabela 6). Entretanto, com 10,0 t ha ${ }^{-1}$ não houve diferença entre os plantios de maio e setembro. Com 5,0 e 15,0 $\mathrm{t} \mathrm{ha}^{-1}$, a biomassa foi maior nos plantios de setembro e maio, respectivamente. Para quaisquer das quantidades de palha adicionadas, o plantio de julho foi o que propiciou menores biomassas de total de tubérculos. Hammerton (1975b) observou, em condição de clima tropical, que temperaturas médias mais altas - como as que ocorrem em setembro - estimulam as plantas de tiririca a distribuir mais biomassa seca para os tubérculos, porém o mesmo não ocorreu nas condições deste experimento quando foi adicionada palha na superficie do solo. Friesen \& Hamill (1977) observaram que, para $C$. esculentus, a umidade do solo afetava o desenvolvimento da planta. Em condições de solo seco e em época em que a pluviosidade é baixa, os tubérculos tornam-se dormentes e sua periodicidade para germinar e desenvolver novos tubérculos é imprevisível. Em condições de solo úmido e precipitação regular, os tubérculos desenvolvem-se rapidamente com o favorecimento da temperatura. Assim, a umidade do solo e a chuva podem ser usadas como indicadores para planejar e adotar medidas de controle mais eficientes. Holt \& Orcutt (1996) classificaram a tiririca como planta $\mathrm{C}_{4}$ por ser altamente competitiva nos períodos em que a temperatura e a intensidade luminosa são elevadas, quando a maioria das culturas torna-se estressada, o que ocorre principalmente no verão (Jackson, 1997). Quando os dias são curtos e secos ocasião em que a maioria das culturas não se desenvolve - a tiririca forma tubérculos.
Em relação ao efeito de adição de palha em cada época de plantio, verificou-se que as biomassas secas de raiz e de rizomas de tubérculos plantados em maio e setembro seguiram uma equação do segundo grau, atingindo valores mínimos com a adição de palha na faixa entre 7,8 e 12,2 $\mathrm{t} \mathrm{ha}^{-1}$ (Tabela 6). Para as biomassas secas de total de tubérculos e parte subterrânea total, verificou-se que, no plantio de maio, os menores valores foram obtidos com, respectivamente, 4,3 e 6,1 $\mathrm{t} \mathrm{ha}^{-1}$. No plantio de julho, a adição de palha favoreceu a formação da parte subterrânea, sendo observado aumento linear para quaisquer das variáveis analisadas. No plantio de setembro, verificou-se redução linear nas biomassas secas de total de tubérculos e da parte subterrânea total.

No estudo do efeito de época de amostragem dentro de cada quantidade de palha adicionada, constatou-se que apenas para biomassa seca de raiz não foi observada interação significativa, (dados não apresentados). As biomassas frescas de raiz e frescas e secas de rizomas (Figura 2), total de tubérculos e parte subterrânea total (Figura 3), para quaisquer das quantidades de palha adicionadas, aumentaram linearmente em função do tempo.

Os plantios de maio, julho e setembro mostraram que as biomassas frescas e secas de raiz, rizomas, total de tubérculo e parte subterrânea total aumentaram linearmente em função do tempo (Tabela 7). Na amostragem realizada aos 28 dias, constatou-se que as biomassas frescas de raiz, rizomas e parte subterrânea total foram estatisticamente iguais nos plantios realizados em maio e setembro, sendo observados os menores valores em julho. Aos 56 e 84 dias, as biomassas frescas de raiz, rizomas e parte subterrânea total foram maiores no plantio de setembro e menores em julho. A biomassa fresca de total de tubérculos, em qualquer época de avaliação, foi estatisticamente igual no plantio de setembro e maio e menor em julho (Tabela 7).

A biomassa seca de raiz, em qualquer época de avaliação, foi estatisticamente superior no plantio de setembro em relação a julho (Tabela 8). O mesmo ocorreu para as biomassas secas de rizomas e parte subterrânea total nas avaliações realizadas aos 56 e 84 dias. Aos 

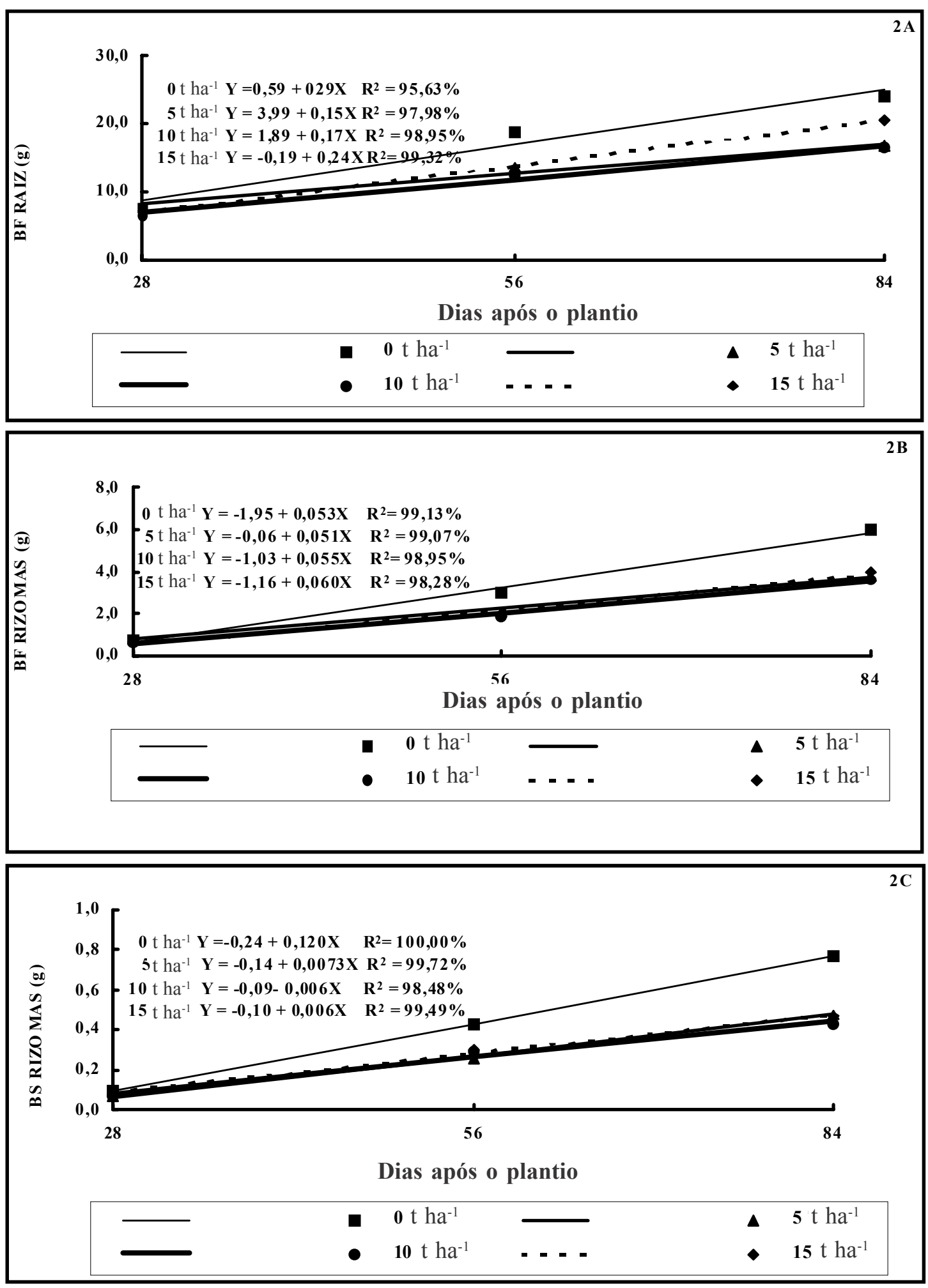

Figura 2 - Efeito da época de amostragem para cada quantidade de palha adicionada quanto às biomassas fresca (BF) de raiz e fresca e seca (BS) de rizomas de tiririca. 
Tabela 7 - Efeito da interação entre épocas de amostragem e de plantio dos tubérculos de tiririca nas biomassas frescas de raiz, rizomas, total de tubérculos e parte subterrânea total

\begin{tabular}{|c|c|c|c|c|c|}
\hline \multirow{4}{*}{$\begin{array}{l}\text { Época de } \\
\text { plantio dos } \\
\text { tubérculos }\end{array}$} & \multicolumn{5}{|c|}{ Biomassa seca de raiz $(\mathrm{g})$} \\
\hline & \multicolumn{3}{|c|}{ Época de amostragem } & \multirow{2}{*}{\multicolumn{2}{|c|}{$\begin{array}{l}\text { Equação de ajuste e coeficiente de } \\
{\text { determinação } 0^{-/}}^{1^{\prime}}\end{array}$}} \\
\hline & 28 dias & 56 dias & 84 dias & & \\
\hline & $8,37 \mathrm{a}^{2 /}$ & $12,62 \mathrm{~b}$ & $19,29 \mathrm{~b}$ & $Y=2,51+0,295 x$ & $\mathrm{R}^{2}=98,36 \%$ \\
\hline Julho & $4,00 \mathrm{~b}$ & $7,11 \mathrm{c}$ & $11,40 \mathrm{c}$ & $Y=0,11+0,132 x$ & $\mathrm{R}^{2}=99,15 \%$ \\
\hline \multirow[t]{2}{*}{ Setembro } & $9,50 \mathrm{a}$ & $23,32 \mathrm{a}$ & $27,52 \mathrm{a}$ & $Y=2,09+0,32 x$ & $\mathrm{R}^{2}=91,35 \%$ \\
\hline & \multicolumn{5}{|c|}{ Biomassa seca de rizomas (g) } \\
\hline Maio & $0,92 \mathrm{a}^{\underline{2} /}$ & $2,40 \mathrm{~b}$ & $4,64 \mathrm{~b}$ & $Y=-1,07+0,067 x$ & $\mathrm{R}^{2}=98,63 \%$ \\
\hline Julho & $0,12 \mathrm{~b}$ & $1,13 \mathrm{c}$ & $1,76 \mathrm{c}$ & $Y=-0,64+0,029 x$ & $\mathrm{R}^{2}=98,33 \%$ \\
\hline \multirow[t]{2}{*}{ Setembro } & $1,12 \mathrm{a}$ & $3,10 \mathrm{a}$ & $6,61 \mathrm{a}$ & $Y=-1,80+0,098 x$ & $\mathrm{R}^{2}=97,50 \%$ \\
\hline & \multicolumn{5}{|c|}{ Biomassa seca de total de tubérculos (g) } \\
\hline Maio & $9,88 \mathrm{a}^{2^{\prime}}$ & $18,39 \mathrm{a}$ & $28,10 \mathrm{a}$ & $Y=0,56+0,33 x$ & $\mathrm{R}^{2}=99,85 \%$ \\
\hline Julho & $4,25 \mathrm{~b}$ & $7,68 \mathrm{~b}$ & $9,66 \mathrm{~b}$ & $Y=1,19+0,11 x$ & $\mathrm{R}^{2}=99,74 \%$ \\
\hline \multirow[t]{2}{*}{ Setembro } & $5,17 \mathrm{a}$ & $18,76 \mathrm{a}$ & $24,20 \mathrm{a}$ & $Y=5,76+0,41 x$ & $\mathrm{R}^{2}=99,03 \%$ \\
\hline & \multicolumn{5}{|c|}{ Biomassa seca de parte subterrânea total (g) } \\
\hline Maio & $19,20 \mathrm{a}^{\frac{2}{}}$ & $35,55 \mathrm{~b}$ & $39,30 \mathrm{~b}$ & $Y=11,24+0,36 x$ & $\mathrm{R}^{2}=88,44 \%$ \\
\hline Julho & $8,30 \mathrm{~b}$ & $16,01 \mathrm{c}$ & $24,27 \mathrm{c}$ & $Y=0,23+0,29 x$ & $\mathrm{R}^{2}=99,96 \%$ \\
\hline Setembro & $18,78 \mathrm{a}$ & $51,16 \mathrm{a}$ & $81,26 \mathrm{a}$ & $Y=12,08+1,12 x$ & $\mathrm{R}^{2}=99,96 \%$ \\
\hline
\end{tabular}

${ }^{1 /}$ Equações de regressão e coeficientes de determinação para o efeito da época de amostragem dentro de cada época de plantio dos tubérculos de tiririca. ${ }^{2 /}$ Médias seguidas por letras iguais na coluna, que comparam o efeito da época de plantio de tubérculo de tiririca em cada época de amostragem, não diferem entre si pelo teste de Tukey a 5\%.

Tabela 8 - Efeito da interação entre épocas de amostragem e de plantio dos tubérculos de tiririca nas biomassas secas de raiz, rizomas, total de tubérculos e parte subterrânea total

\begin{tabular}{|c|c|c|c|c|c|}
\hline \multirow{2}{*}{$\begin{array}{l}\text { Época de } \\
\text { plantio dos } \\
\text { tubérculos }\end{array}$} & \multicolumn{3}{|c|}{ Biomassa seca de raiz $(\mathrm{g})$} & \multirow{2}{*}{\multicolumn{2}{|c|}{$\begin{array}{l}\text { Equação de ajuste e coeficiente de } \\
\text { determinação } 0^{-1}\end{array}$}} \\
\hline & 28 dias & 56 dias & 84 dias & & \\
\hline Maio & $0,68 \mathrm{~b}^{-2}$ & $1,60 \mathrm{~b}$ & $2,27 \mathrm{~b}$ & $Y=-0,074+0,028 x$ & $\mathrm{R}^{2}=99,09 \%$ \\
\hline Julho & $0,33 \mathrm{c}$ & $0,81 \mathrm{c}$ & $1,17 \mathrm{c}$ & $Y-0,068+0,015 x$ & $\mathrm{R}^{2}=99,40 \%$ \\
\hline \multirow[t]{2}{*}{ Setembro } & $1,04 \mathrm{a}$ & $2,06 \mathrm{a}$ & $3,05 \mathrm{a}$ & $Y=0,033+0,036 x$ & $\mathrm{R}^{2}=99,99 \%$ \\
\hline & \multicolumn{3}{|c|}{ Biomassa seca de rizomas (g) } & & \\
\hline Maio & $0,15 \mathrm{a}^{2 /}$ & $0,36 \mathrm{~b}$ & $0,47 \mathrm{~b}$ & $Y=0,0026+0,0057 x$ & $\mathrm{R}^{2}=97,05 \%$ \\
\hline Julho & $0,06 \mathrm{c}$ & $0,17 \mathrm{c}$ & $0,24 \mathrm{c}$ & $Y=-0,092+0,0041 x$ & $\mathrm{R}^{2}=94,70 \%$ \\
\hline \multirow[t]{2}{*}{ Setembro } & $0,09 \mathrm{~b}$ & $0,43 \mathrm{a}$ & $0,90 \mathrm{a}$ & $Y=-0,344+0,0146 x$ & $\mathrm{R}^{2}=99,18 \%$ \\
\hline & \multicolumn{3}{|c|}{ Biomassa seca de total de tubérculos (g) } & & \\
\hline Maio & $2,17 \mathrm{a}^{2 /}$ & $5,76 \mathrm{a}$ & $9,22 \mathrm{~b}$ & $Y=0,56+0,33 x$ & $\mathrm{R}^{2}=99,85 \%$ \\
\hline Julho & $1,09 \mathrm{~b}$ & $2,28 \mathrm{~b}$ & $4,01 \mathrm{c}$ & $\mathrm{Y}=1,19+0,11 \mathrm{x}$ & $\mathrm{R}^{2}=99,74 \%$ \\
\hline \multirow[t]{2}{*}{ Setembro } & $1,51 \mathrm{a}$ & $6,12 \mathrm{a}$ & $10,33 \mathrm{a}$ & $Y=5,76+0,41 x$ & $\mathrm{R}^{2}=99,03 \%$ \\
\hline & \multicolumn{3}{|c|}{ Biomassa seca de parte subterrânea total (g) } & & \\
\hline Maio & $3,22 \mathrm{a}^{2 /}$ & $8,04 \mathrm{~b}$ & $12,40 \mathrm{~b}$ & $Y=-1,23+0,16 x$ & $\mathrm{R}^{2}=99,91 \%$ \\
\hline Julho & $1,49 \mathrm{~b}$ & $3,71 \mathrm{c}$ & $6,17 \mathrm{c}$ & $Y=-0,90+0,084 x$ & $\mathrm{R}^{2}=99,92 \%$ \\
\hline Setembro & $2,88 \mathrm{a}$ & $9,79 \mathrm{a}$ & $18,55 \mathrm{a}$ & $Y=-5,26+0,28 x$ & $\mathrm{R}^{2}=99,54 \%$ \\
\hline
\end{tabular}

${ }^{1 /}$ Equações de regressão e coefícientes de determinação para o efeito de cada época de plantio dos tubérculos de tiririca nas épocas de amostragem. ${ }^{2 /}$ Médias seguidas por letras iguais na coluna, que comparam o efeito de época de plantio de tubérculo de tiririca em cada época de amostragem, não diferem entre si pelo teste de Tukey a $5 \%$. 
28 dias, a biomassa seca de rizoma foi maior em maio. Aos 28 e 56 dias, a biomassa seca do total de tubérculos foi igual nos plantios de maio e setembro, porém, aos 84 dias, foi maior em setembro.

Concluiu-se que: de maneira geral, o tamanho maior dos tubérculos favoreceu o desenvolvimento da parte subterrânea, com
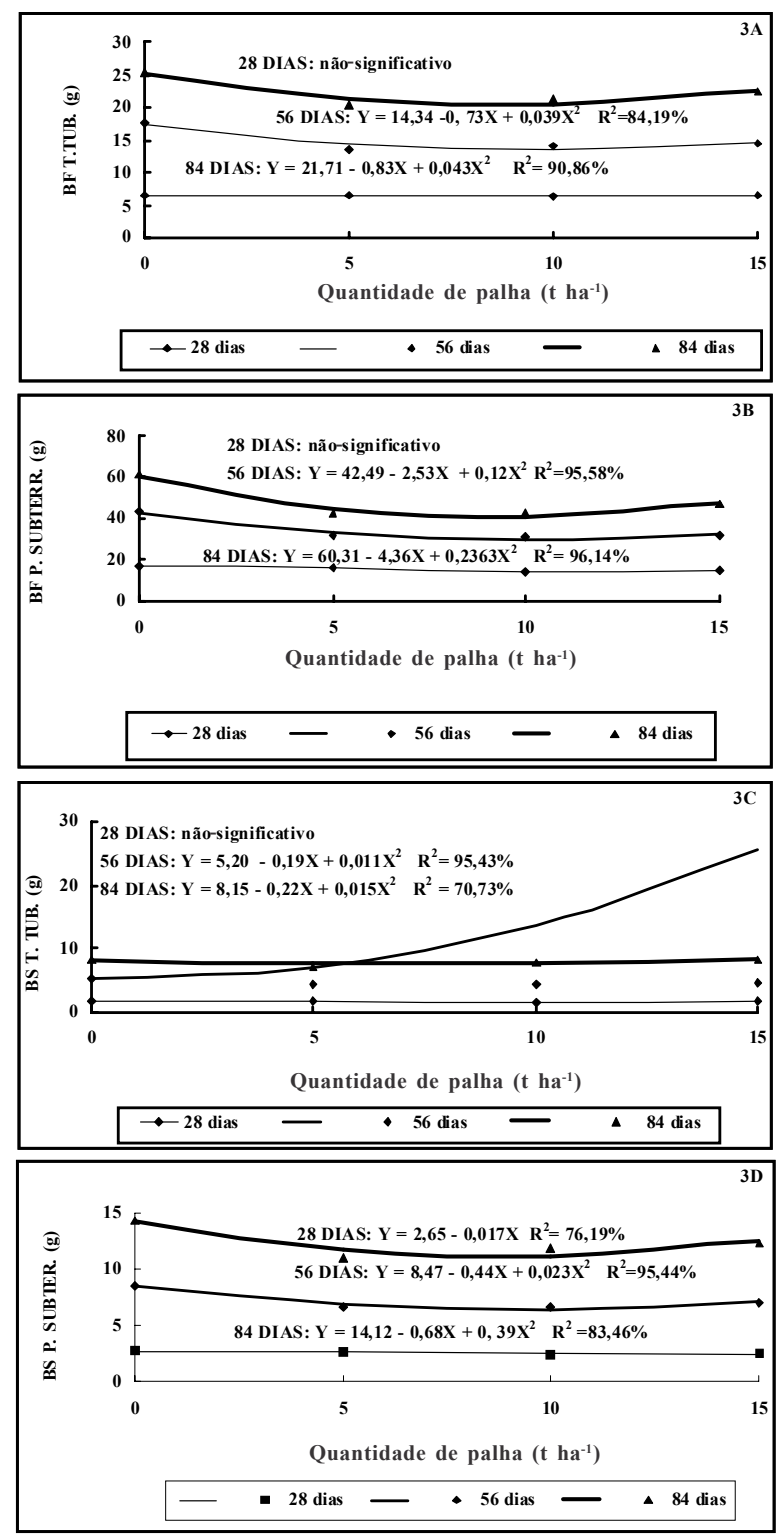

Figura 3 - Efeito da época de avaliação para cada quantidade de palha adicionada quanto às biomassas secas (BS) do total de tubérculos (T. TUB.) e parte subterrânea total (P. SUBTER.) de tiririca. as plantas originadas de tubérculos de tamanho grande apresentando maiores biomassas fresca e seca; a adição de quantidades crescentes de palha de cana-de-açúcar causou redução no desenvolvimento das diferentes estruturas subterrâneas, seguindo, para todas as variáveis, uma equação de segundo grau. Com relação ao efeito de época de amostragem, ocorreram aumentos lineares em função do tempo para todas as variáveis analisadas.

\section{LITERATURA CITADA}

ANDERSEN, R. N. Influence of soybean seed size on response to atrazine. Weed Sci., v. 18, p. 162-164, 1970.

AZANIA, A. A. P. M. et al. Influência da palha de cana-deaçúcar (Saccharum spp) na emergência de espécies de plantas daninhas da família Convolvulaceae. Planta Daninha, v. 20, n. 2, p. 207-212, 2002.

BLACK, J. N. Seed size as a factor in the growth of subterranean clover (Trifolium subterraneum) under spaced and sward conditions. Aust. J. Agric. Res., v. 8, p. 335-351, 1957.

EDWARDS JR, C. J.; HARTWIG, E. E. Effect of seed size upon rate of germination in soybeans. Agron. J., v. 63, p. $429-430,1971$.

EVANS, L. E.; BHATT, G. M. Influence of seed size, protein content, and cultivar on early seedling vigor in wheat. Can. J. Plant Sci., v. 57, p. 929-936, 1977.

FRIESEN, G. H.; HAMILL, A. S. Sprouting and development of yellow nutsedge tubers. Can. J. Plant Sci., v. 57, n. 2, p. 509-514, 1977.

GELMOND, H. Physiological aspects of seed germination. Seed Sci. Technol., v. 6, p. 625-639, 1978.

GROSS, K. L. Effects of seed size and growth form on seedling establishment of six monocarpic perennial plants. J. Ecol., v. 72, p. 369-387, 1984.

HAMMERTON, J. L. Experiments with Cyperus rotundus L. II. Effects of some herbicides and growth regulators.

Weed Res., v. 15, p. 177-183, 1975a.

HAMMERTON, J. L. Experiments with Cyperus rotundus L. III. Seasonal variations in growth. Weed Res., v. 15, p. $339-348,1975 b$.

HAMMERTON, J. L. Effects of desiccation, chemicals and defoliation on nutgrass (Cyperus rotundus $\mathrm{L}$.). In: BRAITHWAITE, C. W. D.; PHELPS, R. H.; BENNETT, F. D. Crop protection in the Caribbean. Trinidad: University of West Indies, 1975c. p. 195-209.

Planta Daninha, Viçosa-MG, v. 23, n. 3, p. 437-448, 2005 
HOLM, L. G. et al. The world's worst weeds: distribution and biology. Honolulu: University Press Hawaii, 1977. $609 \mathrm{p}$.

HOLT, J. S.; ORCUTT, D. R. Functional relationships of growth and competitiveness in perennial weeds and cotton (Gossypium hirsutum). Weed Sci., v. 39, p. 575-584, 1996.

JACKSON, N. Nutsedge in turfgrass: distribution and management in residential and commercial turfgrasses. In: NUTSEGDE MANAGEMENT WORKSHOP. Riverside: University of California. 1997. http://cnas.ucr.edu/ bps/ nutsedge.htm [21-10-98]. p.4-5.

JORDAN-MOLERO, J. E.; STOLLER, E. W. Seasonal development of yellow and purple nutsedge (Cyperus esculentus and C. rotundus) in Illinois. Weed Sci., v. 26, p. $614-618,1978$.

JUSTICE, O. L.; WHITEHEAD, M. D. Seed production, viability and dormancy in nutgrasses (Cyperus rotundus and C. esculentus L.). J. Agric. Res., v. 73, p. 303-318, 1946.

LAFOND, G. P.; BAKER, R. J. Effects of genotype and seed size on speed of emergence and seedling vigor in nine spring wheat cultivars. Crop Sci., v. 26, p. 341-346, 1986.

LIU, M. C.; OWEN, M. D. K. Effect of seed reserve utilization on wooly cupgrass (Eriochloa villosa) development. Weed Sci., v. 51, p. 78-82, 2003.

MARTINS, D. et al. Emergência em campo de dicotiledôneas infestantes em solo coberto com palha de cana-de-açúcar. Planta Daninha, v. 17, n. 1, p. 151-161, 1999.
MILES, J. E.; KAWABATA, O; NISHIMOTO, R. K. Modelling purple nutsedge sprouting under soil solarization. Weed Sci., v. 50, p. 64-71, 2002.

MILES, J. E. R.; NISHIMOTO, R. K.; KAWABATA, O. Diurnally alternating temperatures stimulate sprouting of purple nutsedge (Cyperus rotundus) tubers. Weed Sci., v. 44, p. 122-125, 1996.

PROCÓPIO, S. O. et al. Efeito do tamanho de sementes sobre a tolerância do feijoeiro ao s-metolachlor em condições de baixa temperatura. R. Bras. Herb., v. 2, p. 133-141, 2001.

SILVA, J. R. V.; COSTA, N. V.; MARTINS, D. Efeito da palhada de cultivares de cana-de-açúcar na emergência de Cyperus rotundus L. Planta Daninha, v. 21, n. 3, p. $375-380,2003$.

STOLLER, E. W.; SWEET, R. D. Biology and life cycle of purple and yellow nutsedge (Cyperus rotundus and C. esculentus). Weed Technol., v. 1, p. 66-73, 1987.

VIDAL, R. A.; THEISEN, G. Efeito da cobertura do solo sobre a mortalidade de sementes de capim-marmelada em duas profundidades de solo. Planta Daninha, v. 17, n. 3, p. 339-344, 1999

WEIS, I. M. The effects of propagule size on germination and seedling growth of Mirabilis hirsuta. Can. J. Bot., v. 60 , p. $1868-1874,1982$.

WILLS, G. D. Effect of light and temperature on growth of purple nutsedge. Weed Sci., v. 23, p. 93-96, 1975. 